\title{
Characterizing the Microstructure of Corrosion Films Formed on Zircaloy-4 Using Focused Ion Beam (FIB) Serial Sectioning and 3-D Reconstruction
}

\author{
G. Lucadamo, R. Bajaj, K. R. Anderson, S.R. Claves and J.A. Gruber \\ Bechtel Marine Propulsion Corporation, P.O. Box 79, West Mifflin, PA 15122
}

In this work, focused ion beam (FIB) methods were applied to improve the understanding of corrosion in zirconium alloys. Zirconium alloys are used extensively in the nuclear power industry as fuel cladding material because of their strength and low neutron cross section. However, during exposure to a hot water environment, these alloys develop a porous oxide corrosion film, $\mathrm{ZrO}_{2}$, that has a significantly lower thermal conductivity compared to the metal thus reducing heat transfer. The oxidation of zirconium alloys occurs in two stages. The first stage typically is described by a sub-parabolic growth law and is followed by a "breakdown" in the oxide integrity leading to an increase in the corrosion rate [1,2]. The corrosion process is cyclic in nature, as evidenced by periodic layers of cracks or pores that are frequently observed in the oxide film [2-4]. The layered nature of the structure is believed to be related to underlying mechanisms related to the kinetic transition. Therefore, microstructure characterization is essential to understanding the kinetics of oxidation.

However, metallographic cross-sectioning techniques introduce artifacts in the oxide film [2]. Further, light optical microscopy (LOM) is unable to clearly resolve porosity and cracks. These limitations can be overcome by sectioning and imaging using a dual-beam FIB instrument. Ion milling does not subject the specimen to mechanical stresses that are involved with metallographic grinding and polishing. The FIB also enables serial sectioning to provide a 3-D rendering that shows the arrangement of cracks and pores within a volume of oxide.

In this work, serial sectioning was conducted using a coupon of alpha annealed, Zircaloy-4 exposed for 3113 days to $316^{\circ} \mathrm{C}\left(600^{\circ} \mathrm{F}\right)$ water in an autoclave. The final corrosion film thickness was $\sim 12.9$ $\mu \mathrm{m}$. A Pt layer was first deposited on the surface to protect the underlying oxide during ion milling and a volume was defined by three trenches (Fig. 1a). Sectioning was performed using a nominal slice thickness of $50 \mathrm{~nm}$ with a $30 \mathrm{kV}, 1 \mathrm{nA}$ ion beam. The milling extended through the entire oxide film into the metal. The metal-oxide interface is clearly visible in the cross-section micrographs (Fig. 1b). After alignment and segmentation of the images, an averaging technique was employed to improve the fidelity of locating the crack layers in the oxide film (Fig. 2a).

The processed images confirmed that the crack density varied periodically as a function of depth in the oxide (Fig. 2b,c). The average spacing between crack layers was $1.8 \pm 0.4 \mu \mathrm{m}$, which is consistent with other literature results [2-4]. A 3-D reconstruction revealed that the cracks undulated and were discontinuous within the layers. An average of $2.2 \%$ porosity was measured using the segmented images. High-resolution SEM images of the sectioned face provided details regarding the film microstructure and revealed the location and microstructure of presumably oxidized second phase precipitates in the oxide film and the unique interior morphology of the cracks. The images did not reveal obvious connectivity between crack layers. The layer spacing measured in this alpha annealed film was also similar to that measured using this technique for a beta-quenched Zircaloy-4 coupon tested under similar conditions. 


\section{References:}

[1] B. Cox, J. Nucl. Mater. 29 (1969) 50.

[2] J.S. Bryner, J. Nucl. Mater. 82, (1979) 84.

[3] P. Bossis, et al., Zirconium in the Nuclear Industry: Twelfth International Symposium, ASTM STP 1534, G.P. Sabol and G.D. Moan, Eds. ASTM, Conshohocken, PA 2000, p. 945

[4] A. Yilzmazbayhan, et al., J. Nucl. Mater. 349 (2006) 265.
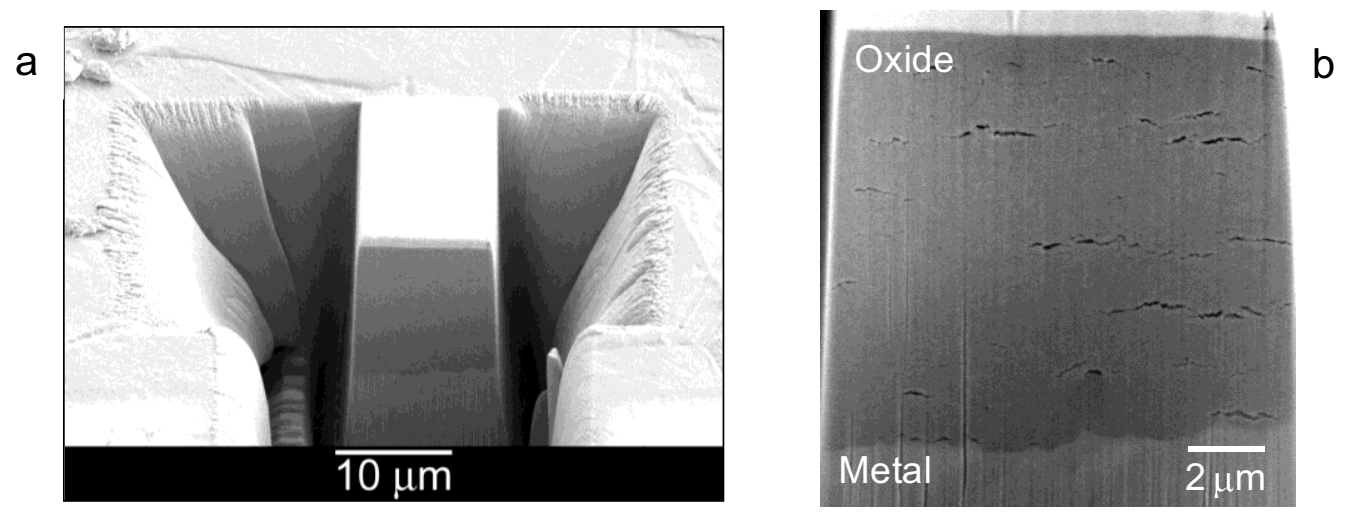

Fig. 1: a) SEM image showing the configuration of the trenches prior to serial sectioning. b) SEM image of the sectioned face revealing metal-oxide interface and microcracks within the oxide film.
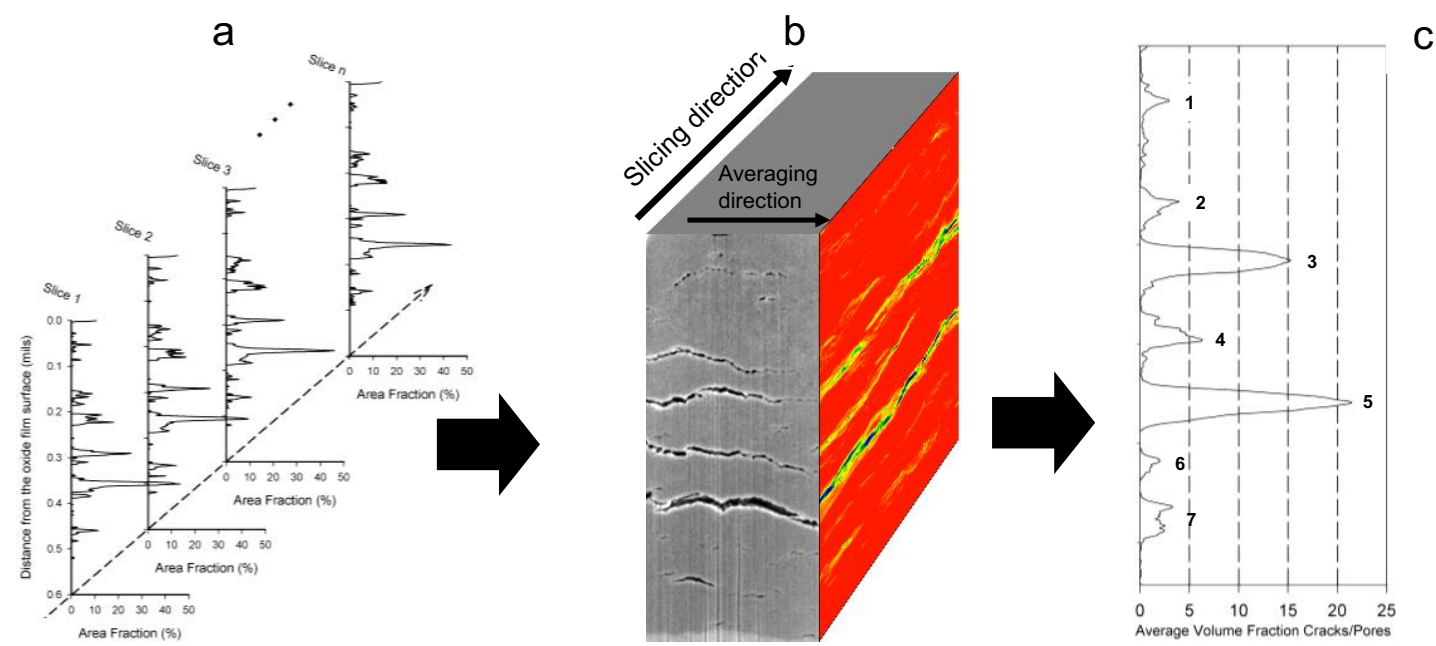

Fig. 2: a) Plots of averaged intensity profiles (area fractions of porosity) obtained from serial section images. b) Illustration of averaged intensity profiles for the volume. c) 3-D average showing peaks corresponding to microcrack/pore locations as a function of depth. 